\title{
Molecular characterization of microbial communities in the rhizosphere soils and roots of diseased and healthy Panax notoginseng
}

\author{
Zhaoxiang Wu $\cdot$ Zhipeng Hao • \\ Yan Zeng • Lanping Guo $\cdot$ Luqi Huang • \\ Baodong Chen
}

Received: 2 March 2015/Accepted: 17 August 2015/Published online: 22 August 2015

(C) Springer International Publishing Switzerland 2015

\begin{abstract}
Rhizosphere and root-associated microbial communities are known to be related to soil-borne disease and plant health. In the present study, the microbial communities in rhizosphere soils and roots of both healthy and diseased Panax notoginseng were analyzed by high-throughput sequencing of $16 \mathrm{~S}$ rRNA for bacteria and $18 \mathrm{~S}$ rRNA internal transcribed spacer for fungi, to reveal the relationship of microbial community structure with plant health status. In total,
\end{abstract}

Electronic supplementary material The online version of this article (doi:10.1007/s10482-015-0560-x) contains supplementary material, which is available to authorized users.

Z. Wu $\cdot$ Z. Hao $\cdot$ B. Chen $(\bowtie)$

State Key Laboratory of Urban and Regional Ecology, Research Center for Eco-Environmental Sciences, Chinese Academy of Sciences, Beijing 100085, China e-mail: bdchen@rcees.ac.cn

Z. Wu

University of Chinese Academy of Sciences,

Beijing 100049, China

Y. Zeng

China National Group Corporation of Traditional and

Herbal Medicine, Beijing 100097, China

L. Guo $\cdot$ L. Huang

State Key Laboratory of Dao-di Herbs, National Resource Center for Chinese Materia Medica, China Academy of

Chinese Medical Sciences, Beijing 100700, China
5593 bacterial operational taxonomic units (OTUs) and 963 fungal OTUs were identified in rhizosphere soils, while 1794 bacterial and 314 fungal OTUs were identified from root samples respectively. Principal coordinate analysis separated the microbial communities both in the rhizosphere soils and roots of diseased $P$. notoginseng from healthy plants. Compared to those of healthy $P$. notoginseng, microbial communities in rhizosphere soils and roots of diseased plants showed a decrease in alpha diversity. By contrast, bacterial community dissimilarity increased and fungal community dissimilarity decreased in rhizosphere soils of diseased plants, while both bacterial and fungal community dissimilarity in roots showed no significant difference between healthy and diseased plants. Redundancy analysis at the phylum level showed that mycorrhizal colonization and soil texture significantly affected microbial community composition in rhizosphere soils, whereas shoot nutrition status had a significant effect on microbial community composition in root samples. Our study provided strong evidence for the hypothesis that microbial diversity could potentially serve as an indicator for disease outbreak of medicinal plants, and supported the ecological significance of microbial communities in maintaining plant healthy and soil fertility.

Keywords Root-rot disease $\cdot$ P. notoginseng · Rhizosphere soil · Illumina MiSeq · Microbial community 


\section{Introduction}

Plant roots and rhizosphere soils are colonized by a great number of microorganisms, such as bacteria and fungi. In rhizosphere soils, microbial communities are directly influenced by living roots through plant root exudates, mucilage and sloughed-off root cells (Brimecombe et al. 2001). Rhizosphere microorganisms play important roles in element cycling in soil ecosystems, and are thought to be critically important with respect to plant health and soil fertility. Symbioses between plants and soil microbes such as endophytic bacteria and arbuscular mycorrhizal (AM) fungi are widespread and especially important in ecosystem functioning. For instance, plant growthpromoting rhizobacteria (PGPR) and AM fungi can enhance plant nutrition, improve plant growth and protect host plants from infection by pathogens. For these reasons, there have been a large number of studies on rhizosphere microbial communities under various circumstances. Better knowledge of microbial diversity in rhizosphere soils and roots of agricultural crops could facilitate the development of soil management strategies to improve plant health and nutrition.

Soil microorganisms play important roles in soil functioning and plant health (van Elsas et al. 2007), and microbial diversity and community composition in soil were thought to be highly relevant to soil-borne diseases (Guo et al. 2005). Many previous studies suggested that healthy plants exhibit higher soil microbial diversity compared to diseased plants (Bakker et al. 2010; Brussaard et al. 2007), while organic amendments could significantly improve microbial diversity. It has been reported that microbial diversity in the rhizosphere soils negatively correlated with occurrence of soil borne disease and positively correlated with the plant resistance to pathogens (Bailey and Lazarovits 2003; Bulluck and Ristaino 2002; Gamliel et al. 2000). For example, fungal diversity was found to be negatively correlated with the incidence of brown stem rot of adzuki bean due to Acremonium gregatum (Nitta 1991), and Qiu et al. (2012) found that disease severity index was lower in bio-fertilizer treatment with a higher microbial diversity. However, soil microbial communities generally exhibit high functional redundancy, and it is now widely accepted that key functional species could be as important as the total microbial diversity (Griffiths et al. 2001). Qiu et al. (2012) found that declined abundance of Fusarium oxysporum and increased abundance of Trichoderma sp. after the amendments of organic fertilizers contributed to disease suppression. Consequently, microbial diversity was not always effective to independently predict soil health (Donegan et al. 1996), while microbial community diversity in combination with community composition, especially for the functional microbial consortia, could be a more meaningful measure.

Panax notoginseng (Burk.) F. H. Chen (Sanqi in Chinese) is an important medicinal plant with high economic and medicinal value, widely used for curing cardiovascular diseases, inflammation, some body pains, trauma, and traumatism with internal and external bleeding (Sun et al. 2005). So far, $P$. notoginseng has only been found in mountain areas with altitude ranging from 1200 to $2000 \mathrm{~m}$ of Wenshan Zhuang and Miao Autonomous Prefecture, Yunnan Province, China (Guo et al. 2010). Generally, $P$. notoginseng is shade cultivated without tillage and is allowed to grow for at least 3 years to develop roots. The long growth period, shaded and humid planting conditions provided suitable environment for the development of several diseases, such as black spot, grey mould, round spot and root rot (Ma et al. 2013). Of these diseases, the root-rot disease complex (RRDC) is the most destructive disease affecting $P$. notoginseng during the whole growth period and could decrease the biological yield by 5-20\%, sometimes exceeding $70 \%$. RRDC has become a serious problem in $P$. notoginseng cultivation as it could cause substantial economic losses for local farmers.

The root-rot disease of $P$. notoginseng is considered to be one of the most complicated plant diseases as it could be caused by bacterial pathogens, fungal pathogens and parasitic nematodes alone or simultaneously (Miao et al. 2006). However, most studies on this disease considered only one or two microbial groups and seldom took into consideration the vast microbial diversity that coexists in roots and rhizosphere soils of $P$. notoginseng. As beneficial microorganisms and pathogens are likely to interact in rhizosphere soils and plant roots which would substantially influence plant health, it is therefore essential to address the entire microbial community when studying the mechanism of the root-rot disease and developing efficient biological control strategies. 
Therefore, the present study was aimed to characterize microbial communities in rhizosphere soils and roots of healthy and diseased $P$. notoginseng through field investigation and molecular characterization of microbial diversity and community composition. We hypothesized that: (1) microbial diversity is higher in healthy $P$. notoginseng than in diseased plants; (2) Healthy and diseased plants exhibit different microbial community compositions in rhizosphere soils and roots; (3) The abundance of pathogens and beneficial microorganisms (such as AM fungi) is relevant to plant health status.

\section{Materials and methods}

The study area and sampling

Nineteen $P$. notoginseng plantations located in Wenshan and Yanshan County of Wenshan Zhuang and Miao Autonomous Prefecture, Yunnan Province were chosen as sampling sites (Table 1 and Fig. S1). These plantations represented the typical cultivation system in this region with $P$. notoginseng plants of $2-4$ years old rotated with other cash crops by local farmers. In December 2011, the sampling sites showed disease incidence from 5 to $70 \%$. In each plantation, 15 healthy plants and 15 diseased plants were collected according to the plant shoot appearance, and these plants were further examined to confirm root-rot disease. Then three to five identified healthy $(\mathrm{H})$ and root-rot diseased (D) plants were randomly selected. The healthy plants exhibited no symptom of necrosis on roots and shoots (Fig. S2 a \& b), while the diseased plants exhibited wilted and etiolated shoots with clear symptoms of necrosis on roots (Fig. S2 c \& d). Each sample was a mixture of 3-5 P. notoginseng plants. Plant roots were gently shaken to remove the loosely adhering soil. Rhizosphere soil was carefully collected from fine roots by gently scraping adhering soil using fine forceps. Each soil sample was placed in a sterile plastic bag, kept on ice, and transported to the laboratory within $4 \mathrm{~h}$. After transportation to the laboratory, the soil samples were passed through $2 \mathrm{~mm}$ mesh to remove plant debris, thoroughly homogenized and divided into subsamples. Subsamples for molecular analysis were stored at $-80{ }^{\circ} \mathrm{C}$, and subsamples for analysis of soil physico-chemical properties were air-dried. Plant materials were washed with tap water three times and shoots and roots were separated at the base of stem. Shoots were oven dried at $70{ }^{\circ} \mathrm{C}$ for further analysis. Roots were separated into
Table 1 Geographical coordinates of the sampling sites and the plant age

\begin{tabular}{|c|c|c|c|c|}
\hline & Latitude & Longitude & Altitude (m) & Plant age \\
\hline 1 & $23^{\circ} 37^{\prime} 23.92^{\prime \prime} \mathrm{N}$ & $104^{\circ} 25^{\prime} 35.63^{\prime \prime} \mathrm{E}$ & 1579 & 2 \\
\hline 2 & $23^{\circ} 10^{\prime} 38.23^{\prime \prime} \mathrm{N}$ & $104^{\circ} 12^{\prime} 47.49^{\prime \prime} \mathrm{E}$ & 1434 & 2 \\
\hline 3 & $23^{\circ} 29^{\prime} 52.51^{\prime \prime} \mathrm{N}$ & $104^{\circ} 17^{\prime} 25.80^{\prime \prime} \mathrm{E}$ & 1614 & 2 \\
\hline 4 & $23^{\circ} 10^{\prime} 48.68^{\prime \prime} \mathrm{N}$ & $104^{\circ} 13^{\prime} 08.29^{\prime \prime} \mathrm{E}$ & 1410 & 2 \\
\hline 5 & $23^{\circ} 10^{\prime} 46.52^{\prime \prime} \mathrm{N}$ & $104^{\circ} 13^{\prime} 06.43^{\prime \prime} \mathrm{E}$ & 1404 & 2 \\
\hline 6 & $23^{\circ} 34^{\prime} 54.74^{\prime \prime} \mathrm{N}$ & $103^{\circ} 51^{\prime} 16.36^{\prime \prime} \mathrm{E}$ & 1488 & 2 \\
\hline 7 & $23^{\circ} 11^{\prime} 8.56^{\prime \prime} \mathrm{N}$ & $104^{\circ} 13^{\prime} 9.87^{\prime \prime} \mathrm{E}$ & 1469 & 2 \\
\hline 8 & $23^{\circ} 11^{\prime} 0.72^{\prime \prime} \mathrm{N}$ & $104^{\circ} 13^{\prime} 37.67^{\prime \prime} \mathrm{E}$ & 1550 & 2 \\
\hline 9 & $23^{\circ} 10^{\prime} 57.47^{\prime \prime} \mathrm{N}$ & $104^{\circ} 13^{\prime} 47.36^{\prime \prime} \mathrm{E}$ & 1452 & 2 \\
\hline 10 & $23^{\circ} 13^{\prime} 31.03^{\prime \prime} \mathrm{N}$ & $104^{\circ} 12^{\prime} 15.37^{\prime \prime} \mathrm{E}$ & 1590 & 2 \\
\hline 11 & $23^{\circ} 34^{\prime} 56.96^{\prime \prime} \mathrm{N}$ & $104^{\circ} 19^{\prime} 51.38^{\prime \prime} \mathrm{E}$ & 1552 & 2 \\
\hline 12 & $23^{\circ} 42^{\prime} 31.00^{\prime \prime} \mathrm{N}$ & $104^{\circ} 25^{\prime} 11.07^{\prime \prime} \mathrm{E}$ & 1524 & 3 \\
\hline 13 & $23^{\circ} 18^{\prime} 28.35^{\prime \prime} \mathrm{N}$ & $104^{\circ} 20^{\prime} 44.85^{\prime \prime} \mathrm{E}$ & 1390 & 3 \\
\hline 14 & $23^{\circ} 18^{\prime} 29.18^{\prime \prime} \mathrm{N}$ & $104^{\circ} 20^{\prime} 43.14^{\prime \prime} \mathrm{E}$ & 1382 & 3 \\
\hline 15 & $23^{\circ} 18^{\prime} 11.29^{\prime \prime} \mathrm{N}$ & $104^{\circ} 20^{\prime} 39.14^{\prime \prime} \mathrm{E}$ & 1366 & 3 \\
\hline 16 & $23^{\circ} 11^{\prime} 0.86^{\prime \prime} \mathrm{N}$ & $104^{\circ} 13^{\prime} 27.03^{\prime \prime} \mathrm{E}$ & 1552 & 3 \\
\hline 17 & $23^{\circ} 13^{\prime} 48.43^{\prime \prime} \mathrm{N}$ & $104^{\circ} 12^{\prime} 39.84^{\prime \prime} \mathrm{E}$ & 1593 & 3 \\
\hline 18 & $23^{\circ} 13^{\prime} 53.53^{\prime \prime} \mathrm{N}$ & $104^{\circ} 12^{\prime} 1.63^{\prime \prime} \mathrm{E}$ & 1684 & 3 \\
\hline 19 & $23^{\circ} 10^{\prime} 36.63^{\prime \prime} \mathrm{N}$ & $104^{\circ} 12^{\prime} 55.01^{\prime \prime} \mathrm{E}$ & 1396 & 4 \\
\hline
\end{tabular}


three parts for further analyses, a $1 \mathrm{~g}$ subsample of the fine root was stored at $-80{ }^{\circ} \mathrm{C}$ for molecular analysis, another $1 \mathrm{~g}$ subsample of fine root stored at $4{ }^{\circ} \mathrm{C}$ for measuring mycorrhizal colonization and arbuscule abundance, and the remaining part was dried for determination of elemental concentrations.

\section{Sample analysis}

Soil $\mathrm{pH}$ was determined using glass electrode $\mathrm{pH}$ meter (FE20-Five Easy Plus ${ }^{\mathrm{TM}}$, Switzerland) in a 1:2.5 soil/water (w/v) suspension (Qiu et al. 2012), and soil organic carbon (SOC) was determined by the $\mathrm{K}_{2} \mathrm{Cr}_{2} \mathrm{O}_{7}$ oxidation-reduction titration method (Page et al. 1982). Soil inorganic nitrogen was assayed by using the alkaline hydrolysis method (Cornfield 1960) and soil available phosphorus $(\mathrm{P})$ by Mo-Sb colorimetry method (Gyaneshwar et al. 2002). Soil available potassium (K) was measured following standard protocols as described by McLean and Watson (1985). Total nitrogen (N), total carbon (C) and total sulphur (S) of soil and plant samples were measured by direct combustion using an elemental analyzer (Vario EL III, Germany), and C/N was calculated based on total $\mathrm{C}$ and total N. Soil particle-size was analyzed by a laser particle size analyzer (Malvern, UK). Mycorrhizal colonization (M \%) and arbuscular abundance (A \%) were measured according to the method described by Phillips and Hayman (1970).

DNA extraction and sequencing

Soil DNA was extracted from a $0.5 \mathrm{~g}$ subsample of each soil sample using the Fast DNA ${ }^{\circledR}$ SPIN Kit for Soil (MP Biomedicals, Solon, Ohio, USA). Total DNA of the root samples was extracted from homogenized root materials using the CTAB method according to the protocol of Stewart and Via (1993). The extracted total DNA, dissolved in $30 \mu \mathrm{l}$ sterilized deionized water, was checked on a $1 \%$ agarose gel and the DNA concentration and quality was estimated using a Nanodrop ${ }^{\circledR}$ ND-2000 UV-Vis Spectrophotometer (NanoDrop Technologies, USA). Amplicon libraries for bacteria were produced by using bacteriaspecific primers $515 \mathrm{~F}$ and $806 \mathrm{R}$ designed for the V4 region of 16S rRNA gene according to Bergmann et al. (2011). Each pair of primers used to amplify a certain sample was barcoded with a unique error-correcting 10-12 bases barcode on both forward and reverse primers. All amplifications were performed in twofold $25 \mu \mathrm{l}$ reactions, including $1 \mu \mathrm{l}$ of template DNA $(20 \mathrm{ng} / \mu \mathrm{l}), 1 \mu \mathrm{l}$ of each primer $\left(10 \mathrm{pmol}^{-1} \mathrm{l}^{-1}\right)$, $12.5 \mu \mathrm{l}$ of $2 \times$ PCR reaction mix (TAKARA Biotechnology Co. Ltd), and $0.5 \mu \mathrm{l}$ of Taq DNA polymerase (2.5 $\mathrm{U}^{-1}$; TAKARA Biotechnology Co. Ltd). The protocol of amplification was as follows: $5 \mathrm{~min}$ initial denaturation at $95{ }^{\circ} \mathrm{C}$, followed by 35 cycles of denaturation for $45 \mathrm{~s}$ at $94{ }^{\circ} \mathrm{C}, 45 \mathrm{~s}$ primer annealing at $58{ }^{\circ} \mathrm{C}, 1 \mathrm{~min}$ extension at $72{ }^{\circ} \mathrm{C}$, and a final $10 \mathrm{~min}$ extension at $72{ }^{\circ} \mathrm{C}$. Amplicon libraries for fungi were prepared using an identical approach, except that we chose a specific primer pair ITS1F and ITS2 (Rajala et al. 2012), designed for the internal transcribed spacer (ITS) 1 region for Illumina sequencing. PCR products were purified by agarose gel electrophoresis with a QIAquick PCR Purification Kit (QIAEX II Gel Extraction Kit, QIAGEN Sciences, Maryland), estimated by using a Nanodrop ${ }^{\circledR}$ ND-2000 UV-Vis Spectrophotometer (NanoDrop Technologies, USA) and mixed together with equal amount of $150 \mathrm{ng}$ for each sample. The pooled samples were sent to Chinese National Human Genome Center, Shanghai, China and sequenced on an Illumina Miseq 2000 platform (Illumina, San Diego, CA, USA).

\section{Sequence analysis}

Data yielded from Illumina sequencing was analyzed with the bioinformatics platform Mothur (v.1.33.0), as described previously by Schloss et al. (2009). For bacteria, all the raw sequence data obtained was assigned to each sample based on their barcode sequence. Reads with an average quality value $<30$ and not having both universal primer sequences were filtered. A total of 758,859 raw bacterial sequences and 591,076 raw fungal sequences were obtained from rhizosphere soils of healthy and diseased plants. After quality control, removal of chimeras and non-target sequences, 423,617 bacterial sequences (ranging from 4267 to 20,732 sequences per sample) for bacteria and 527,195 fungal sequences (ranging from 5439 to 33,627 sequences per sample) were used for further analysis. Similarly, a total of 919,104 raw bacterial sequences and 258,747 fungal raw sequences were obtained from the 38 root samples. After the same data preprocessing, 276,360 bacterial sequences (ranging from 952 to 22,785 sequences per sample) and 121,357 fungal sequences (ranging from 708 to 9771 
sequences per sample) from root samples were used for further analysis.

For bacteria, after removal of primers, all sequences were aligned with the Silva-ARB database (version 119, Pruesse et al. 2007). After chimeras were removed, all sequences were clustered into operational taxonomic units (OTUs) at $97 \%$ identity threshold by using the unsupervised Bayesian clustering algorithm CROP (Hao et al. 2011), and all OTUs were included in downstream analyses. Rarefaction curves of all the samples at a dissimilarity of 0.03 were generated. The rarefaction analysis suggested that the sequences sampled were insufficient to capture the total richness at a genetic distance of 0.03 . To estimate the final ranking, we calculated the abundance-based coverage estimator (ACE) and the estimated asymptotic microbial taxon richness Chao. After an identical number of reads (4,267 and 952 for bacteria in rhizosphere soils and plant roots respectively) were subsampled from each sample, microbial diversity was compared between healthy and diseased plants based on the calculated Shannon index. Finally, sequences were assigned to taxonomic groups by using the RDP classifier (Rel. 11).

For fungi, data were analyzed with an identical procedure except that ITS1 region was extracted from each sequence by Fungal ITS Extractor 1.1 after removal of primers (Henrik Nilsson et al. 2011), and sequences were aligned against the UNITE ITS database (version 6.0, Abarenkov et al. 2010). Furthermore, the identical the numbers of reads subsampled from each sample were 5439 and 708 in rhizosphere soils and plant roots respectively.

Data analysis

All microbial community-related analyses were based on relative abundance of OTUs per sample unless otherwise stated, and the taxonomic community dissimilarity was calculated by using the Bray-Curtis index. Phylogenetic community dissimilarity was calculated by using FastUnifrac (Rodrigues et al. 2013). The pairwise geographic distances between sites were calculated based on geographic coordinates. The relationship between geographic distance and microbial dissimilarity was assessed by regressing the pairwise community dissimilarity against the pairwise geographic distance using linear regression.
Differences in observed parameters between healthy and diseased plants were tested by Paired-T tests with the software package SPSS 18.0 (SPSS Inc., Chicago, IL, USA). In cases involving multiple comparisons, Bonferoni-corrected $P$-values of 0.05 as the level of significance was adopted. Principal coordinate analysis (PCoA) of microbial communities was carried out by using the CANOCO 5.0 software (Microcomputer Power, Ithaca, NY, USA). analysis of similarity (ANOSIM, Clarke 1993), Adonis (permutational multivariate analysis of variance, Clarke and Warwick 2001) and multiple response permutation procedure (MRPP, Woolson and Clarke 2011) were performed based on Bray-Curtis distances by using VEGAN package in R (Oksanen 2011).

To ensure the data met the assumptions of normality, plant biomass, plant and soil $\mathrm{C}, \mathrm{N}$ and $\mathrm{S}$ contents, plant and soil $\mathrm{C} / \mathrm{N}$ ratios, soil available $\mathrm{P}$ and $\mathrm{K}$ and inorganic $\mathrm{N}$ were tested for normality before further analysis by using the Shapiro-Wilk test in SPSS 18.0.

Redundancy analysis (RDA) to identify the effect of environmental factors on bacterial and fungal community composition, based on the relative abundance of the detected phyla in each sample, was carried out with the CANOCO 5.0 software. According to the result of the detrended correspondence analysis (DCA) for the microbial community, the linear ordination method was found to be appropriate for data analysis of both bacterial and fungal communities (gradient lengths $<3$ ). The significant environmental variables $(P<0.05)$ were determined by the manual forward selection procedure implemented in the RDA using a Monte Carlo test with 999 permutations.

\section{Results}

Plant and soil properties

The properties of rhizosphere soils showed no significant difference between healthy and diseased plants except that soil-available $\mathrm{K}$ of diseased plants was significantly higher than healthy plants (Table 2). However, the plant parameters measured were generally lower in diseased plants, except that the shoot dry weight and root $\mathrm{N}$ content showed no significant difference between each other (Table 3). 
Table 2 The physico-chemical properties (mean \pm SE, $\mathrm{n}=19$ ) of rhizosphere soils of P. notoginseng

\begin{tabular}{|c|c|c|c|c|c|c|c|}
\hline & $\mathrm{pH}$ & $\mathrm{SOC}(\mathrm{g} / \mathrm{kg})$ & Olsen-P (mg/kg) & Inorganic $\mathrm{N}(\mathrm{mg} / \mathrm{kg})$ & Avail-K (mg/kg) & $\mathrm{TC}(\%)$ & $\mathrm{TN}(\%)$ \\
\hline $\mathrm{H}$ & $5.69 \pm 0.22$ & $12.37 \pm 0.76$ & $143.81 \pm 14.08$ & $36.38 \pm 2.94$ & $0.23 \pm 0.02$ & $1.53 \pm 0.11$ & $0.12 \pm 0.01$ \\
\hline $\mathrm{D}$ & $5.72 \pm 0.20$ & $12.67 \pm 0.66$ & $147.55 \pm 18.89$ & $34.40 \pm 4.22$ & $0.34 \pm 0.04$ & $1.49 \pm 0.09$ & $0.12 \pm 0.01$ \\
\hline Sig. & NS & NS & NS & NS & $* *$ & NS & NS \\
\hline
\end{tabular}

$H$ healthy plants, $D$ diseased plants, $T C$ total carbon content, $T N$ total nitrogen content, Sig. significance

** $P<0.01 ; \mathrm{NS}, P>0.05$

Table 3 The plant dry weights, $C$ and $N$ contents (mean $\pm S E, n=19)$

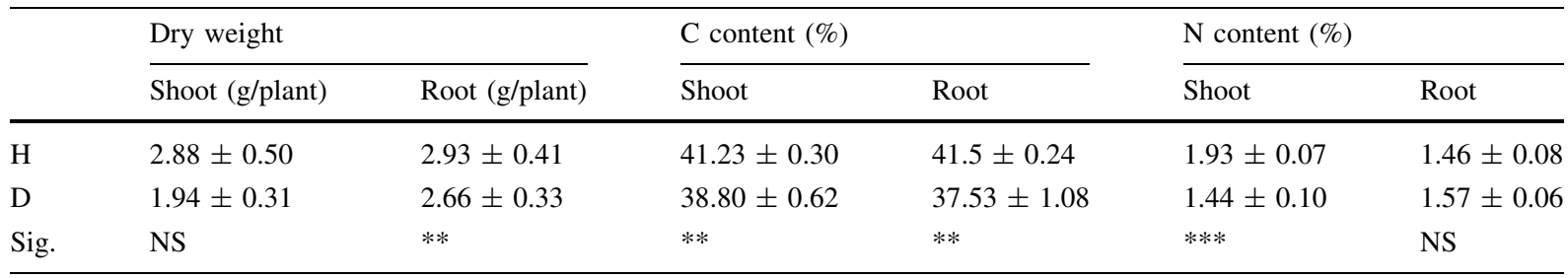

$H$ healthy plants, $D$ diseased plants, Sig. significance

** $P<0.01$; *** $P<0.001$; NS, $P>0.05$

Microbial diversity in rhizosphere soils and plant roots

A total of 5593 bacterial OTUs and 963 fungal OTUs were identified in rhizosphere soils, while 1794 bacterial and 314 fungal OTUs were identified from root samples respectively at a cut-off of $97 \%$ sequence similarity. The bacterial and fungal OTUs detected in both plant roots and rhizosphere soils were more abundant in healthy than diseased $P$. notoginseng (Table 4). Rarefaction curves showed that the number of OTUs increased with the number of sequences obtained in each of the soil/root samples, and none of the curves reached a plateau at $97 \%$ similarity level and sustained crossing (Fig. 3).

In rhizosphere soils and plant roots, Shannon index, ACE and Chao at the dissimilarity of 0.03 for bacteria and fungi were significantly lower in diseased plant compared to healthy plant, except that the fungal ACE showed no significant difference in rhizosphere soils. Overall, the microbial community alpha diversity was significantly lower in rhizosphere soils and roots of diseased plant (Table 4). Bacterial community dissimilarity was significantly higher in rhizosphere soils of diseased plants, while the fungal community dissimilarity showed the opposite trend, which indicated that bacterial community in rhizosphere soils of diseased $P$. notoginseng was more dissimilar and fungal community was more similar in composition. However, microbial community dissimilarity in plant roots showed no significant difference between healthy and diseased plants. These results were also true for both taxonomic and phylogenetic measures of dissimilarity (Figs. 1, 2). Additionally, the relationship between microbial taxonomic diversity and geographic distance showed that only fungal

Table 4 Comparison of the estimated OTU richness and diversity indices of the 16S rRNA (bacteria) and ITS (fungi) libraries in rhizosphere soils and roots of healthy and diseased $P$. notoginseng

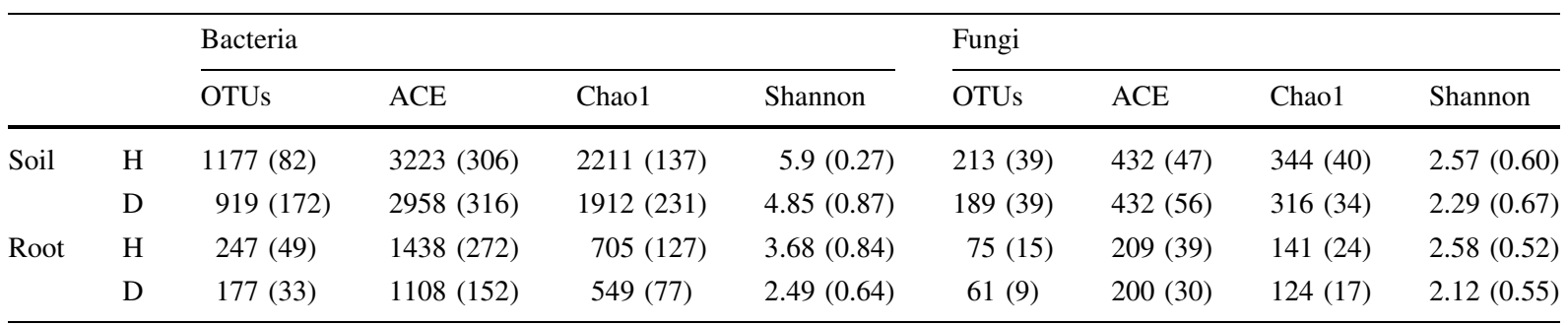

Averages of 19 replicates with standard errors in parenthesis, $H$ healthy plants, $D$ diseased plants 
community in rhizosphere soils of healthy plants exhibited significant change across distance (analysis of covariance: $\mathrm{F}=4.89, P<0.05$, Fig. S4 \& S5).

Microbial communities in rhizosphere soils and plant roots

PCoA based on relative abundance of OTUs separated microbial community in rhizosphere soils and roots of diseased P. notoginseng from healthy plants (Fig. 3). The three non-parametric multivariate statistical tests, ANOSIM, Adonis and MRPP at the species level (97\% identity threshold) indicated significant
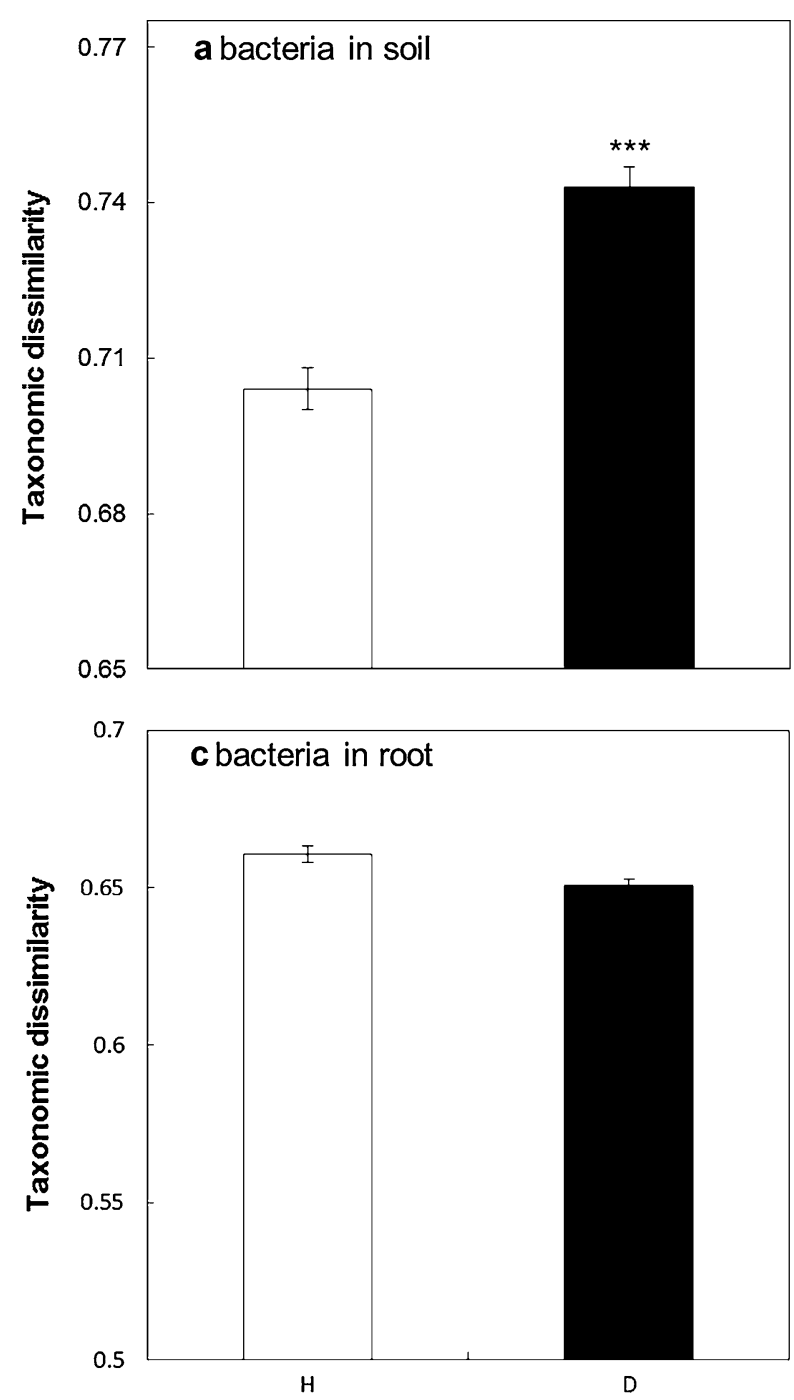

differences in microbial community between healthy and diseased plants (Table 5). These differences were also evident at both phylum level (Table 6) and OTU level (Fig. 3).

By classifying all OTUs into taxonomic groups, we identified 21 bacterial phyla and 5 fungal phyla associated with rhizosphere soils (Table 6). The dominant bacterial phyla in both healthy and diseased plants were Acidobacteria, Actinobacteria, Bacteroidetes, Proteobacteria and Verrucomicrobia. By Paired-T Tests, Acidobacteria, Cyanobacteria, Firmicutes, Verrucomicrobia and WPS1 were found to be less abundant, but Proteobacteria more abundant in
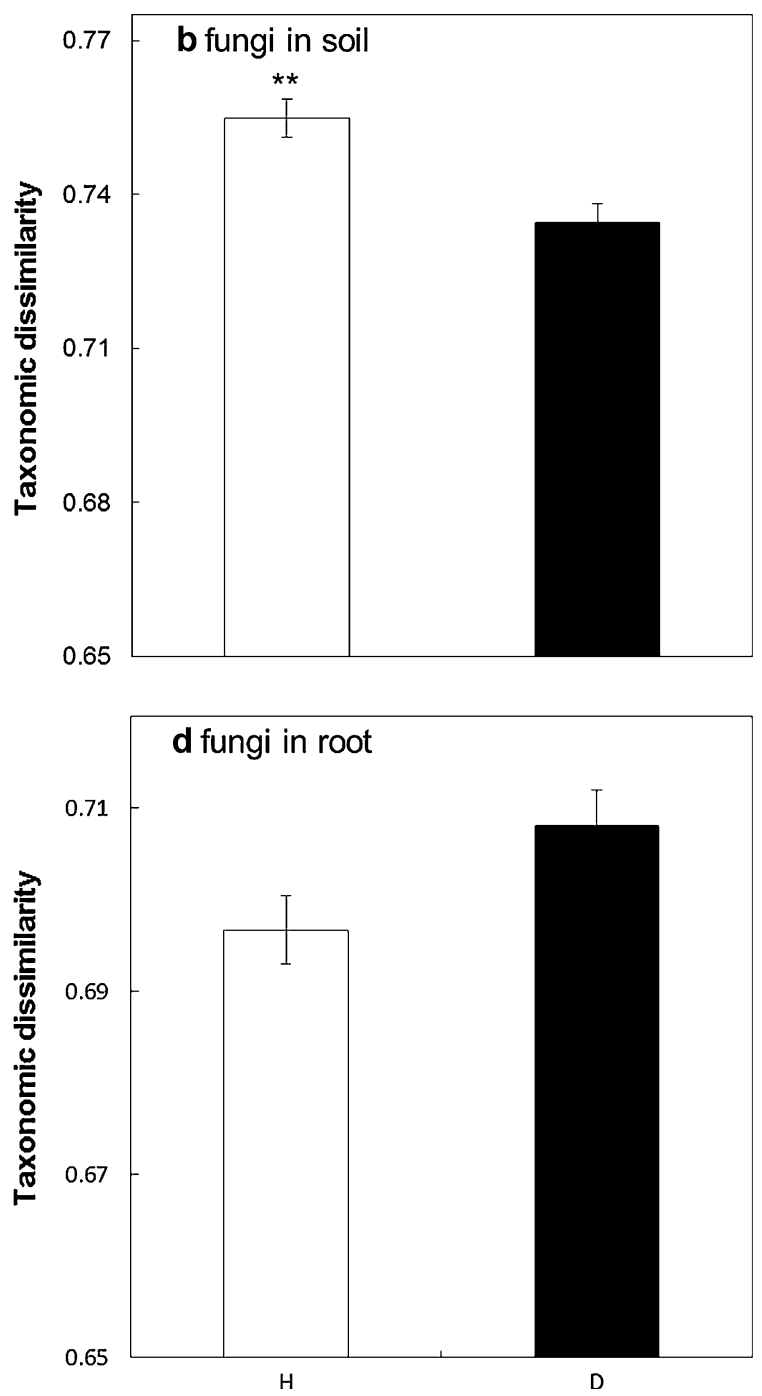

Fig. 1 Comparison on average taxonomic dissimilarity (Bray-Curtis) of microbial communities between healthy and diseased $P$. notoginseng. $H$ healthy plants, $D$ diseased plants. $P$ values post Bonferoni correction were shown. $* * P<0.01 ; * * * P<0.001$ 

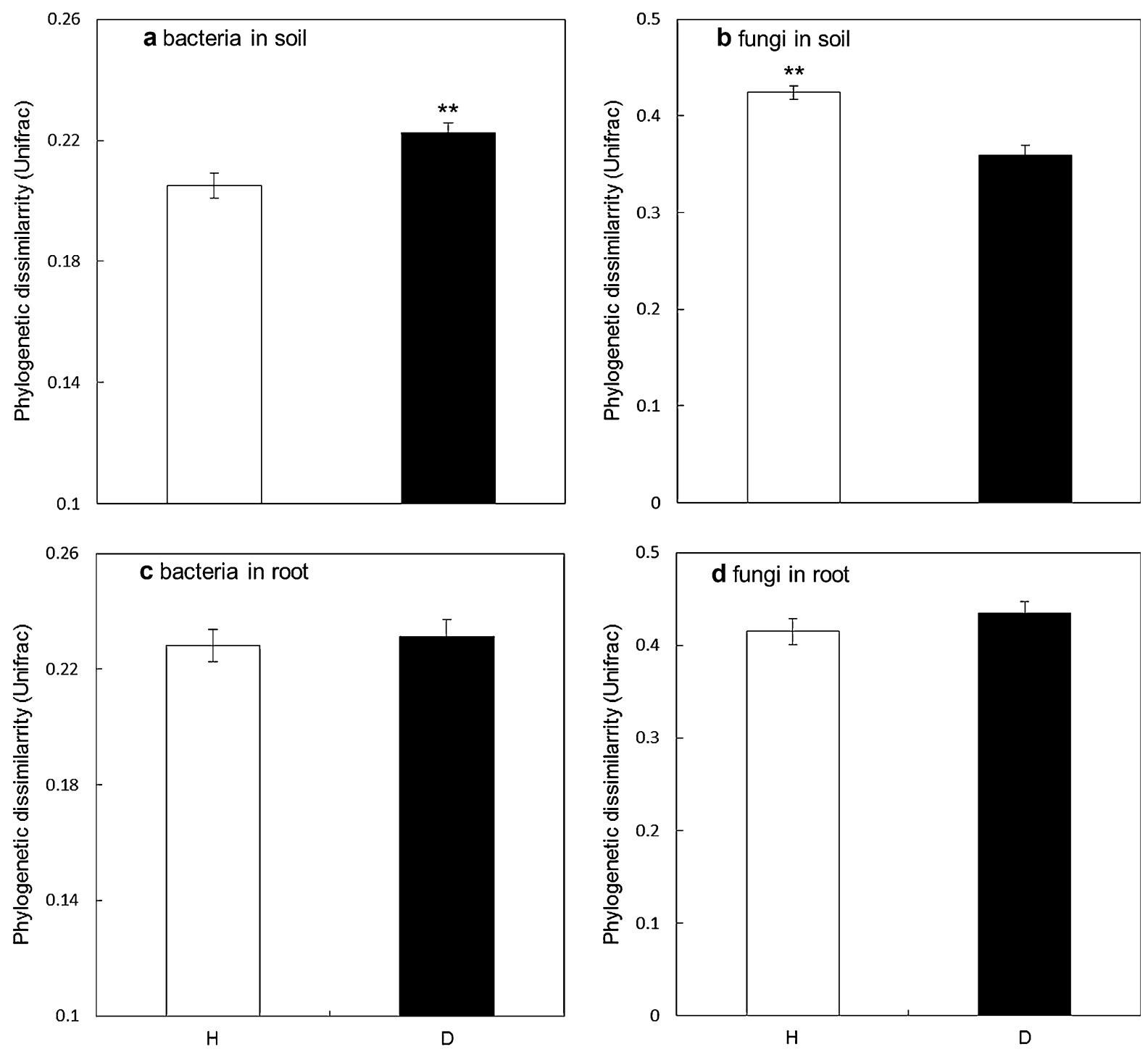

Fig. 2 Comparison on average phylogenetic dissimilarity (FastUniFrac) of microbial communities between healthy and diseased $P$. notoginseng. $H$ healthy plants, $D$ diseased plants. $P$ values post Bonferoni correction were shown. ** $P<0.01$

diseased compared to healthy plants $(P<0.05)$. On the other side, the dominant fungal phyla were Ascomycota, Basidiomycota and Zygomycota. Glomeromycota was less abundant, but Ascomycota more abundant in diseased than healthy plants $(P<0.05)$.

Compared with the microbial communities in rhizosphere soils, fewer bacterial and fungal OTUs were detected in root samples (Table 4), which may be an artifact of the difference in sampling depth. In total 18 bacterial phyla and 5 fungal phyla (Table 6) were captured from the root samples. Acidobacteria,
Actinobacteria, Bacteroidetes, Cyanobacteria and Proteobacteria were found to be the dominant bacterial phyla; Ascomycota, Basidiomycota and Zygomycota were the dominant fungal phyla. Compared to healthy plants, Armatimonadetes, Cyanobacteria, Elusimicrobia and Planctomycetes were less abundant, but Firmicutes and Proteobacteria more abundant in diseased plants $(P<0.05)$. For fungi, Ascomycota was more abundant, but Zygomycota and Glomeromycota were more abundant in diseased than healthy plants $(P<0.05)$. 
Fig. 3 Principal coordinate analyses (PCoA) for bacteria (a and c) and fungi (b and $\mathbf{d}$ ) associated with rhizosphere soils (a and b) and roots (c and d) of $P$. notoginseng. Empty circles represent healthy plants and solid circles represent diseased plants a
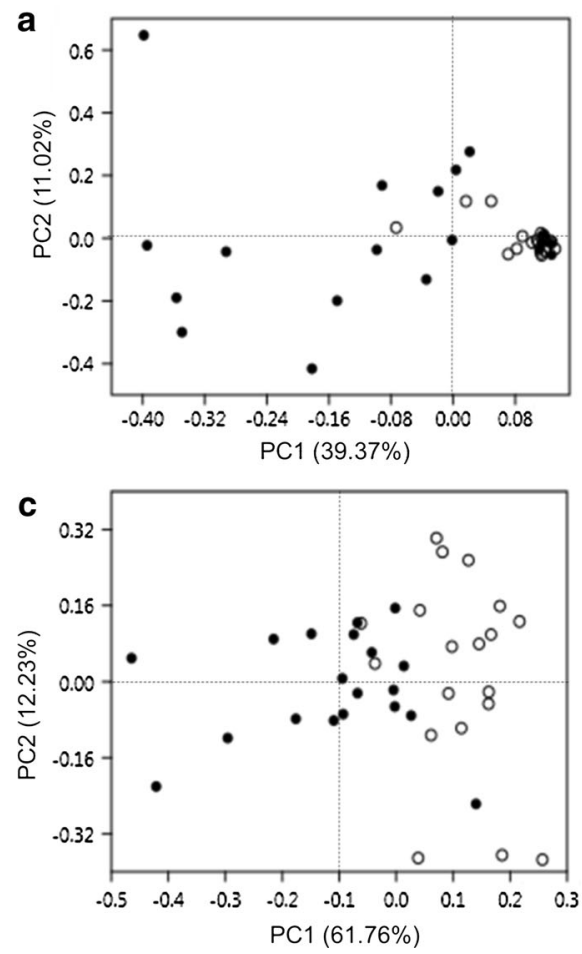

b
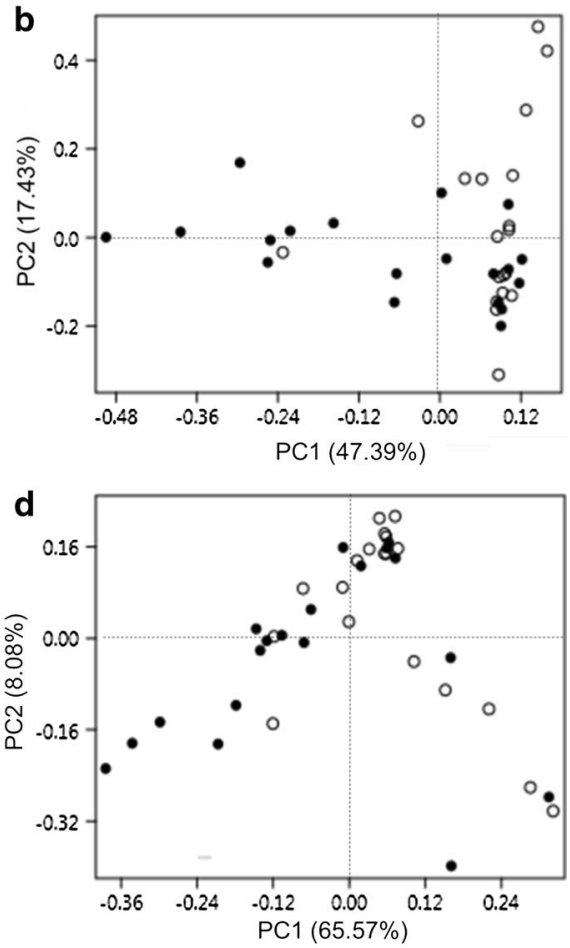

Table 5 Dissimilarity analysis of microbial community composition associated with rhizosphere soils or plant roots between diseased and healthy $P$. notoginseng

\begin{tabular}{|c|c|c|c|c|c|c|c|c|}
\hline \multirow[t]{2}{*}{ Comparisons } & \multicolumn{2}{|c|}{ ANOSIM } & \multicolumn{3}{|c|}{ Adonis } & \multicolumn{3}{|l|}{ MRPP } \\
\hline & $\mathrm{R}$ & $P$ & $\mathrm{R}^{2}$ & $\mathrm{~F}$ & $P$ & Observed $\delta$ & Expected $\delta$ & $P$ \\
\hline Soil bacterium & 0.279 & 0.002 & 0.085 & 3.35 & 0.001 & 0.677 & 0.698 & 0.005 \\
\hline Soil fungi & 0.125 & 0.01 & 0.073 & 2.84 & 0.004 & 0.661 & 0.68 & 0.006 \\
\hline Root bacterium & 0.352 & 0.001 & 0.225 & 10.42 & 0.001 & 0.369 & 0.401 & 0.001 \\
\hline Root fungi & 0.172 & 0.001 & 0.082 & 3.22 & 0.003 & 0.632 & 0.653 & 0.003 \\
\hline
\end{tabular}

$P$ values in bold show the significant difference between healthy and diseased plants

The effects of environmental factors on the microbial community structure

RDA was performed to identify the correlation of environmental factors with microbial community structure associated with rhizosphere soils and roots. In rhizosphere soils, RDA revealed that $\mathrm{M} \%$, soil clay and inorganic $\mathrm{N}$ content were significant predictors for the bacterial communities between the samples (Fig. 4a), and A $\%$ and clay content for fungal communities (Fig. 4b). Generally, M \%, A \%, clay and inorganic $\mathrm{N}$ positively correlated with microbial communities associated with healthy plants.
However, for the microbial communities in roots of $P$. notoginseng, the significant predictors were shoot $\mathrm{S}$ and $\mathrm{C}$ content for bacterial communities (Fig. 4c), and shoot $\mathrm{N}$ content and soil $\mathrm{C} / \mathrm{N}$ ratio for fungal communities (Fig. 4d). These predictors were also positively correlated with microbial communities associated with healthy plants.

\section{Discussion}

By using Illumina MiSeq high-throughput sequencing, we revealed significantly different microbial 
Table 6 Microbial compositions of healthy and diseased $P$. notoginseng at phylum level
Data show the average percentage of phylum proportion in rhizosphere soils and roots of $P$.

\section{notoginseng}

$H$ healthy plants, $D$ diseased plants, Sig. significance

* $P<0.05$; ** $P<0.01$;

$* * * P<0.001 ; \mathrm{NS}$,

$P>0.05$

\begin{tabular}{|c|c|c|c|c|c|c|c|}
\hline & \multirow[t]{2}{*}{ Phylum } & \multicolumn{3}{|c|}{ Rhizosphere soil (\%) } & \multicolumn{3}{|c|}{ Plant roots $(\%)$} \\
\hline & & $\mathrm{H}$ & $\mathrm{D}$ & Sig. & $\mathrm{H}$ & $\mathrm{D}$ & Sig. \\
\hline \multirow[t]{24}{*}{ Bacteria } & Acidobacteria & 16.35 & 9.63 & $* *$ & 1.13 & 1.01 & NS \\
\hline & Actinobacteria & 12.25 & 11.60 & NS & 1.27 & 1.42 & NS \\
\hline & Armatimonadetes & 0.35 & 0.18 & NS & 0.02 & 0.01 & $*$ \\
\hline & Bacteroidetes & 9.60 & 10.10 & NS & 2.78 & 4.45 & NS \\
\hline & $\mathrm{BRC} 1$ & 0.01 & - & NS & - & - & - \\
\hline & WPS1 & 0.92 & 0.33 & $*$ & 0.03 & 0.02 & NS \\
\hline & WPS2 & 0.47 & 0.20 & NS & 0.03 & 0.02 & NS \\
\hline & Saccharibacteria & - & - & - & 0.02 & 0.04 & NS \\
\hline & Chlamydiae & 0.22 & 0.09 & NS & - & - & - \\
\hline & Chloroflexi & 5.52 & 4.02 & NS & 0.28 & 0.25 & NS \\
\hline & Cyanobacteria & 2.82 & 1.66 & $*$ & 67.86 & 43.77 & $* * *$ \\
\hline & Elusimicrobia & - & - & - & 0.23 & 0.12 & $* *$ \\
\hline & Firmicutes & 2.35 & 1.65 & $*$ & 0.17 & 0.23 & $* *$ \\
\hline & Gemmatimonadetes & 2.33 & 1.37 & $* *$ & 0.10 & 0.10 & NS \\
\hline & Latescibacteria & 0.03 & 0.02 & NS & - & - & - \\
\hline & Microgenomates & 0.02 & - & NS & 0.01 & - & NS \\
\hline & Nitrospirae & 0.84 & 0.60 & NS & 0.04 & 0.04 & NS \\
\hline & Parcubacteria & 0.29 & 0.10 & NS & - & - & - \\
\hline & Planctomycetes & 1.40 & 0.69 & $*$ & 0.15 & 0.08 & $* *$ \\
\hline & Proteobacteria & 31.02 & 49.13 & $* * *$ & 24.53 & 47.28 & $* * *$ \\
\hline & Saccharibacteria & 0.53 & 0.50 & NS & - & - & - \\
\hline & Spirochaetes & 0.02 & 0.01 & NS & - & - & - \\
\hline & Verrucomicrobia & 5.06 & 2.85 & $* *$ & 0.40 & 0.32 & $*$ \\
\hline & unclassified & 7.63 & 5.26 & $* *$ & 0.96 & 0.82 & NS \\
\hline \multirow[t]{6}{*}{ Fungi } & Ascomycota & 54.08 & 72.26 & $* *$ & 72.81 & 82.40 & $*$ \\
\hline & Basidiomycota & 10.76 & 7.70 & NS & 12.01 & 10.27 & NS \\
\hline & Chytridiomycota & 0.08 & 0.04 & NS & 0.59 & 0.12 & NS \\
\hline & Glomeromycota & 0.20 & 0.04 & $*$ & 0.05 & 0.03 & NS \\
\hline & Zygomycota & 28.16 & 17.95 & NS & 10.74 & 5.38 & $* *$ \\
\hline & unclassified & 6.72 & 1.99 & NS & 3.79 & 1.79 & $* *$ \\
\hline
\end{tabular}

have only focused on single host-pathogen interactions: an unlikely model of natural situations (Davies and Pedersen 2008). The Illumina sequencing method employed in this study overcame this limitation, and obtained thousands of sequences simultaneously to identify as many microorganisms as possible, which allowed comparison on the microbial community both from rhizosphere soils and roots between diseased and healthy $P$. notoginseng systematically, and also better understanding of microecological changes along with root-rot disease of $P$. notoginseng.

Although the rarefaction curves did not reach saturation in any of the present samples (Fig. 3), which was similar to several previous studies (Lauber 
Fig. 4 RDA of sequence abundance assigned at phylum level of bacterial and fungal communities in the 19 pairs of soil (a and b) and root samples (c and d) in relation to environmental variables. Only Axis 1 was significant. Red lines represent the environmental variables, Empty circles represent healthy plants and solid circles represent diseased plants
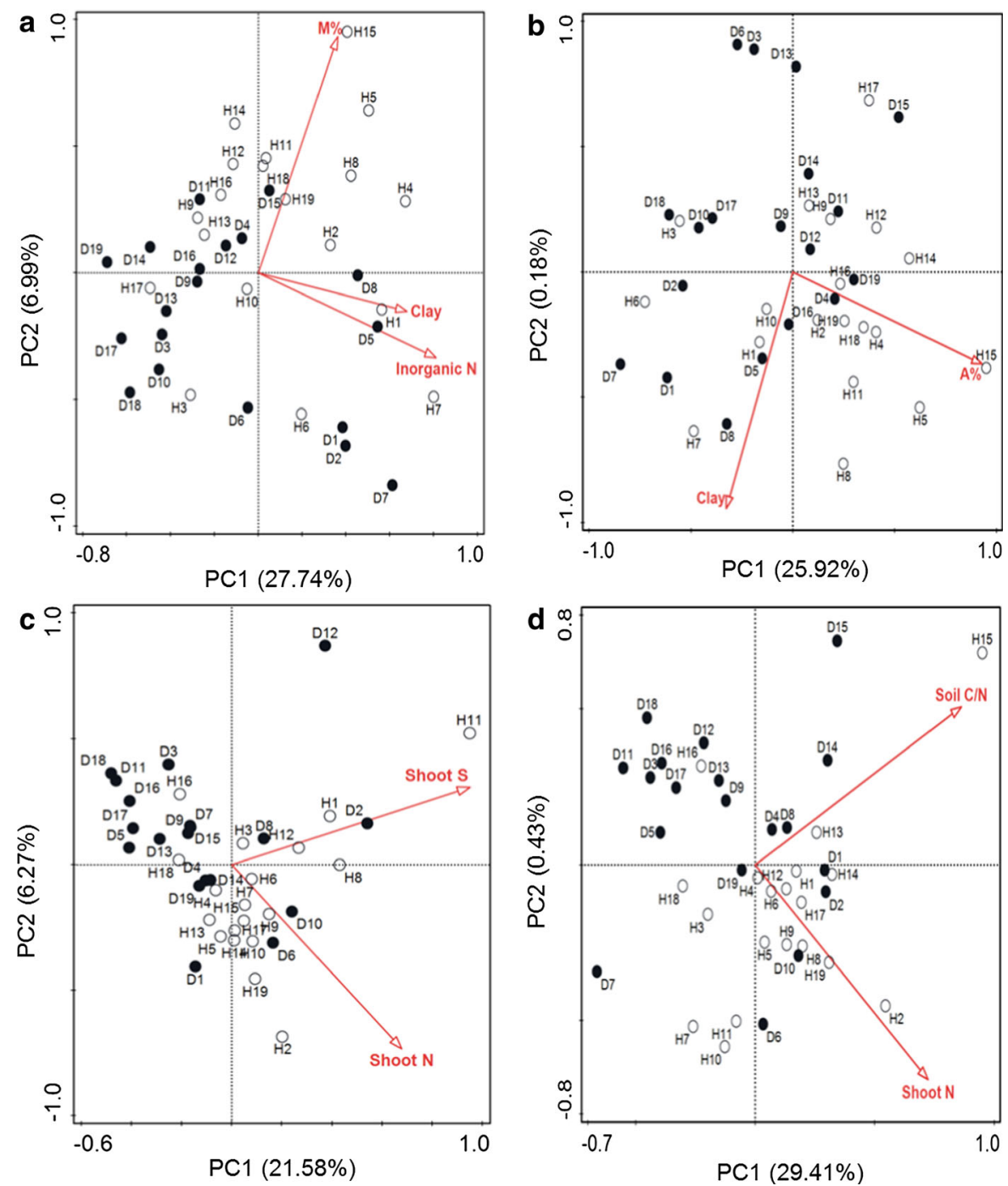

et al. 2009; Teixeira et al. 2010), the data obtained was valid for detecting the differences in microbial community structure between healthy and diseased plants at OTU (Fig. 3; Table 5) and phylum levels (Table 6). However, as an almost infinite number of microorganisms exist in natural and agricultural ecosystems, and each microbial group contributes to macroecology, a deeper sequencing for more denoised sequences per sample is still expected for an accurate and precise description of the microbial communities.

In the present study the microbial diversity was found to be higher in healthy than diseased $P$. notoginseng both in rhizosphere soils and roots. Rhizosphere microbial communities are known to affect plant fitness and soil quality (Lugtenberg and Kamilova 2009). For instance, the diversity index of functional groups of actinomycetes from tomato rhizospheres was found to be negatively correlated with corky root severity caused by P. lycopersici (Van Bruggen and Semenov 1999). In another study, fungal diversity was also negatively correlated with incidence of brown stem rot of adzuki bean caused by $A$. gregatum (Nitta 1991). These results together implied that the disturbed microbial communities might have contributed to root-rot disease, but other reasons like the effect of nematode could not be ruled out.

Besides the change of microbial alpha diversity in rhizosphere soil, microbial dissimilarity also provided 
insights. In rhizosphere soils, fungal communities turned to be more similar in diseased plants (Figs. 1, 2 ), and were similar in different geographic locations $(\mathrm{F}=4.89, P<0.05$, Fig. S4 \& S5), which was an indication of biotic homogenization (Olden et al. 2004). In contrast, bacterial communities were found to be more dissimilar in rhizosphere soils of diseased $P$. notoginseng (Figs. 1, 2), and the taxa shared between healthy and diseased plants were found to be significantly less abundant in soil samples of diseased plants (Fig. 5), compared to that of healthy plants, showing a decrease of bacterial taxa in rhizsopshere soils of diseased plants.

The bacterial and fungal community composition at the phylum (Table 6) and genus levels (Tables S1 \& S2) in rhizosphere soils of $P$. notoginseng generally corresponded with previous studies carried out in agricultural or other soil types for bacteria by deep $16 \mathrm{~S}$ rRNA pyrosequencing (Acosta-Martinez et al. 2008; Roesch et al. 2007), and for fungi by ITS sequencing (Buee et al. 2009). Furthermore, the main bacterial and fungal phyla found in roots were in general accordance with those in rhizosphere soils. Bacterial and fungal communities associated with rhizosphere soils and roots of $P$. notoginseng were clearly linked to plant health status. This was true not only at OTU level (Fig. 3), but also at phylum (Table 6) and genus levels (Tables S1 \& S2). Sanguin et al. (2009) showed that Verrucomicrobia was one of the prevalent phyla during the outbreak of wheat take-all disease, which was different from the finding in the present study that the abundance of this phylum was higher in healthy (5.06\% in rhizosphere soil and $0.40 \%$ in roots) than diseased plants $(2.85 \%$ in rhizosphere soil and $0.32 \%$ in roots). This may be explained by the low relative abundance of Verrucomicrobia accounted for the total sequences, $3.96 \%$ in rhizosphere soil and $0.36 \%$ in roots on average, variation in the initiator of different soil-borne diseases (Van Elsas et al. 2002) and difference in land management (Rescia et al. 1994). In this study, high abundance of Pseudomonas, which was also isolated from rotted root of $P$. notoginseng and exhibited the strongest pathogenicity (Miao et al. 2006), was identified both in rhizosphere soils and roots, and was more abundant in diseased than that in healthy plants (Table S1). In the future, we should pay more attention to this genus, for species of Pseudomonas acted as one predicted pathogen causing root-rot disease of $P$. notoginseng. However, root-rot disease was reported to be caused by number of pathogens including bacteria and fungi (Ma et al. 2013), and other common microbial pathogens such as Lonsdalea species can't be ignored, which was also more abundant in rhizosphere soils of diseased plants.

As for fungi, Ascomycota was the most abundant fungal phylum (accounting for $63.17 \%$ of the total sequences in rhizosphere soil and $77.61 \%$ in roots on average), and was more abundant in diseased than healthy plants, both in rhizosphere soils and roots. The abundance of Ascomycota was much higher than in previous reports (O'Brien et al. 2005). By further analysis at the genus level, 51 abundant genera (more than $1 \%$ of total sequences) were found in rhizosphere soils and 27 in roots (Tables S1 \& S2), but the genera Fusarium and Cylindrocarpon, which were considered to be the main pathogens causing root-rot of $P$. notoginseng (Mao et al. 2014), showed no significant difference between diseased and healthy plants both in rhizosphere soils and in roots. The view point that Fusarium sp. and Cylindrocarpon sp. cause root-rot disease of $P$. notoginseng should be tested by more strict experiments. Interestingly, Ilyonectria, of which multiple species were identified to be pathogens causing plant root-rot disease (Cabral et al. 2012; Vitale et al. 2012), was found to be more abundant both in rhizosphere soils and roots of diseased than healthy $P$. notoginseng. To the best of our knowledge, this genus hasn't previously been reported to be involved in root-rot disease of $P$. notoginseng, but results from the present study may suggest reconsideration of its potential role in root-rot disease.

Additionally, aiming to initiate a biocontrol program of the serious root-rot disease of $P$. notoginseng, microbial community structure at the genus level provided useful information for screening and identification of antagonists. Glomeromycota was detected in rhizosphere soil and roots, and was more abundant in healthy plants (Table 6), which was consistent with the mycorrhizal colonization rates (data not shown). AM fungi that belong to Glomeromycota associate with more than $80 \%$ of vascular land plants and play an important role in natural ecosystems (Vigo et al. 2000). AM fungi benefit plants by supplying mineral nutrients especially phosphorus (Al-Karaki 2006), helping transport water to ease drought stress ( $\mathrm{Li}$ et al. 2013) and increasing plant resistance to soil borne diseases locally or/and systemically (Hao et al. 2012). However, the effect of AM fungi on root-rot of 

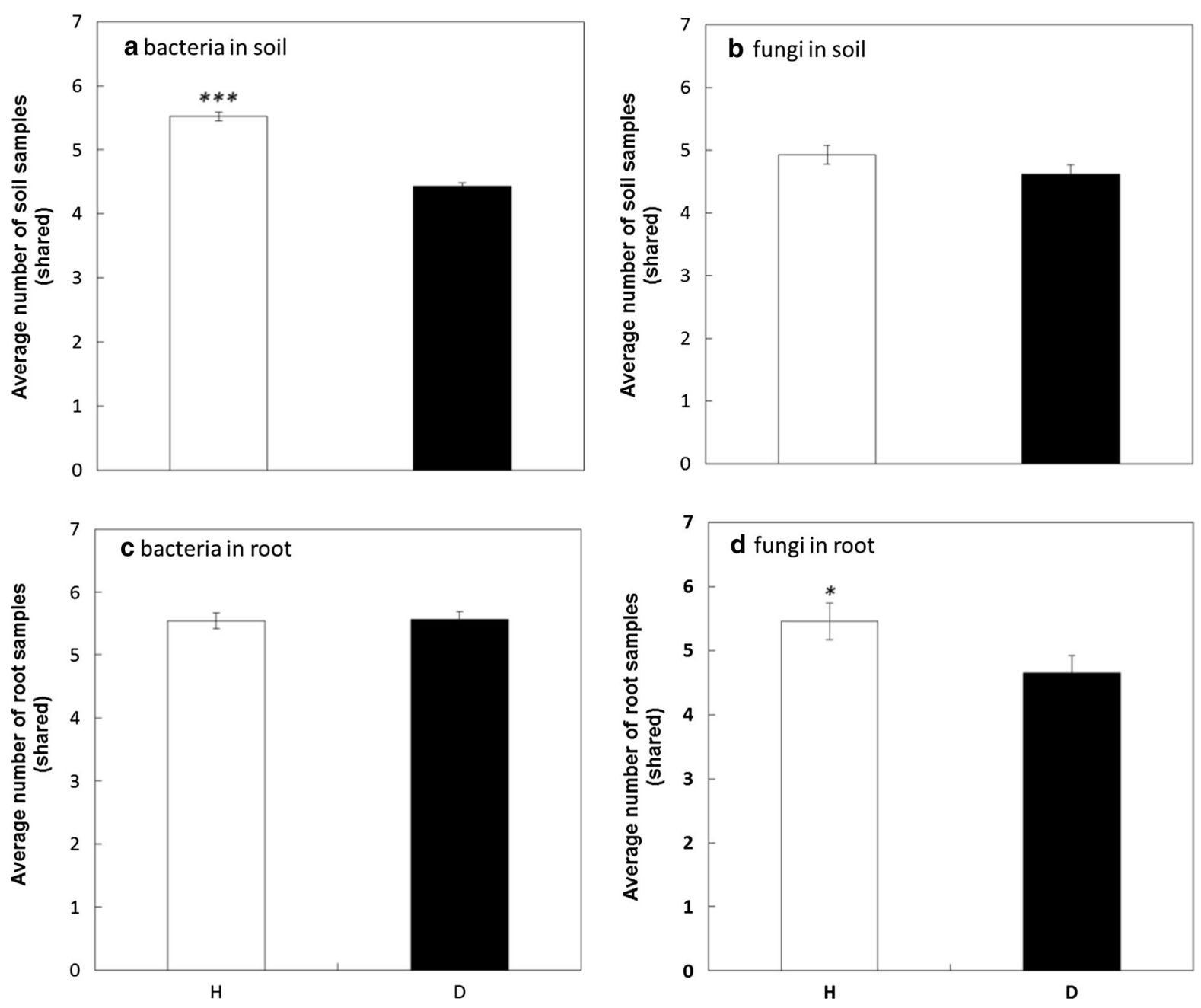

Fig. 5 Distribution of shared OTUs in healthy and diseased plants. a Bacteria in rhizosphere soil. b Fungi in rhizosphere soil. c Bacteria in plant root. d Fungi in plant root. $H$ healthy

P. notoginseng is still unclear. Furthermore, Flavisolibacter, Gemmatimonas, Terrimonas and Mortierella that were more abundant in healthy than diseased plants, could potentially serve as pathogen antagonists and should also be considered in the biocontrol program.

RDA analysis at the phylum level illustrated the relationships between microbial community structure and environmental factors. For bacterial and fungal community in rhizosphere soils, mycorrhizal colonization and clay percentage appeared to be the main regulators of microbial community structure. Clay percentage was positively correlated with enzyme activity as reported by Beyer et al. (1992). Soil texture

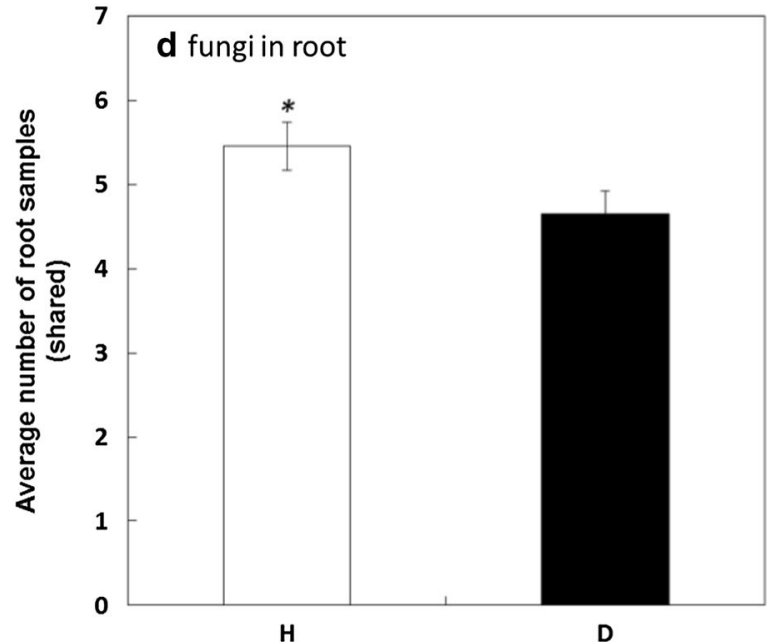

plants, $D$ diseased plants. $P$ values post Bonferoni correction were shown. * $P<0.05$; *** $P<0.001$

has an effect on other soil properties, including water availability and nutrient supply, which could subsequently influence microbial growth and activity (Zeller et al. 2001). Furthermore, a better soil texture could potentially enhance substrate availability of SOC pools, provide more favorable habitats, and protect microbes from predation and other disadvantaged circumstances. Mycorrhizal colonization was found to significantly affect the rhizopshere microbial communities (Jeffries et al. 2003), and was closely linked with plant healthy status. Due to the fact that Glomeromycota was of greater abundance in rhizosphere soils of healthy $P$. notoginseng plants, we may suppose that AM fungi possibly play a role in shaping 
the rhizosphere microbial communities of $P$. notoginseng plants.

In root samples, shoot $\mathrm{S}$ and $\mathrm{C}$ content were found to associate with the shift in bacterial community, and soil $\mathrm{C} / \mathrm{N}$ and shoot $\mathrm{N}$ content associate with fungal community. These elements function in a myriad of fundamental processes, from photosynthesis to signaling pathways and plant physiological response to biotic and abiotic stresses (Droux 2004). As the nutrition status of plant shoot directly influences bacterial and fungal endophytes, inoculation with mycorrhizal fungi and agricultural practices such as tillage and foliar fertilizer could be considered during cultivation of $P$. notoginseng to improve the plant health status.

In conclusion, the results obtained from the present study suggested that (i) microbial community structure in rhizosphere soils and roots of diseased $P$. notoginseng differed significantly from that of healthy plants; (ii) microbial diversity was found to be higher in healthy than diseased $P$. notoginseng both in rhizosphere soils and roots; (iii) The abundance of pathogens and beneficial microorganisms is relevant to plant health status. Moreover, the high throughput sequencing technique does provide a powerful tool to examine microbial communities relevant to plant health status, and it could be employed in following studies on the occurrence mechanism and bio-control of plant diseases.

Acknowledgments The study was financially supported by National Natural Science Foundation of China (41101245) and National Key Technology R\&D Program of the Ministry of Science and Technology (2012BAI29B02). We are grateful to the Prof. Yong Wang in Wenshan Sanqi Institute of Wenshan University for identifying the root-rot disease of $P$. notoginseng.

\section{Compliance with ethical standards}

Ethical approval This article does not contain any studies with human participants or animals performed by any of the authors.

\section{References}

Abarenkov K, Henrik Nilsson R, Larsson KH, Alexander IJ, Eberhardt U, Erland S, Høiland K, Kjøller R, Larsson E, PennanenT Sen R, Taylor AF, Tedersoo L, Ursing BM, Vrälstad T, Liimatainen K, Peintner U, Kõljalg U (2010) The UNITE database for molecular identification of fungi- recent updates and future perspectives. New Phytol 186(2):281-285

Acosta-Martinez V, Dowd S, Sun Y, Allen V (2008) Tag-encoded pyrosequencing analysis of bacterial diversity in a single soil type as affected by management and land use. Soil Biol Biochem 40(11):2762-2770

Al-Karaki GN (2006) Nursery inoculation of tomato with arbuscular mycorrhizal fungi and subsequent performance under irrigation with saline water. Sci Hortic 109(1):1-7

Bailey KL, Lazarovits G (2003) Suppressing soil-borne diseases with residue management and organic amendments. Soil Tillage Res 72(2):169-180

Bakker MG, Glover JD, Mai JG, Kinkel LL (2010) Plant community effects on the diversity and pathogen suppressive activity of soil streptomycetes. Appl Soil Ecol 46(1):35-42

Bergmann GT, Bates ST, Eilers KG, Lauber CL, Caporaso JG, Walters WA, Knight R, Fierer N (2011) The under-recognized dominance of Verrucomicrobia in soil bacterial communities. Soil Biol Biochem 43(7):1450-1455

Beyer L, Wachendorf C, Balzer FM, Balzer-Graf UR (1992) The effect of soil texture and soil management on microbial biomass and soil enzyme activities in arable soils of Northwest Germany. Agribiol Res (Germany) 45:276-283

Brimecombe MJ, De Leij FA, Lynch JM (2001) The effect of root exudates on rhizosphere microbial populations. In: Pinton R, Varanini Z, Nannipieri P (eds) The rhizosphere biochemistry and organic substances at the soil-plant interface. Marcel Dekker, New York, pp 95-140

Brussaard L, De Ruiter PC, Brown GG (2007) Soil biodiversity for agricultural sustainability. Agric Ecosyst Environ 121(3):233-244

Buee M, Reich M, Murat C, Morin E, Nilsson RH, Uroz S, Martin F (2009) 454 Pyrosequencing analyses of forest soils reveal an unexpectedly high fungal diversity. New Phytol 184(2):449-456

Bulluck LR III, Ristaino JB (2002) Effect of synthetic and organic soil fertility amendments on southern blight, soil microbial communities, and yield of processing tomatoes. Phytopathology 92(2):181-189

Cabral A, Groenewald JZ, Rego C, Oliveira H, Crous PW (2012) Cylindrocarpon root rot: multi-gene analysis reveals novel species within the Ilyonectria radicicola species complex. Mycol Prog 11(3):655-688

Clarke KR (1993) Non-parametric multivariate analyses of changes in community structure. Aust $\mathrm{J}$ Ecol 18(1):117-143

Clarke KR, Warwick RM (2001) Change in marine communities: an approach to statistical analysis and interpretation, 2nd edn. PRIMER-E, Plymouth

Cornfield AH (1960) Ammonia released on treating soils with $\mathrm{N}$ sodium hydroxide as a possible means of predicting the nitrogen-supplying power of soils. Nature 187:260-261

Davies TJ, Pedersen AB (2008) Phylogeny and geography predict pathogen community similarity in wild primates and humans. Proc R Soc B 275(1643):1695-1701

Donegan KK, Schaller DL, Stone JK, Ganio LM, Reed G, Hamm PB, Seidler RJ (1996) Microbial populations, fungal species diversity and plant pathogen levels in field plots of potato plants expressing the Bacillus thuringiensis var. tenebrionis endotoxin. Transgenic Res 5(1):25-35 
Droux M (2004) Sulfur assimilation and the role of sulfur in plant metabolism: a survey. Photosynth Res 79(3):331-348

Gamliel A, Austerweil M, Kritzman G (2000) Non-chemical approach to soilborne pest management-organic amendments. Crop Prot 19(8):847-853

Griffiths BS, Ritz K, Wheatley R, Kuan HL, Boag B, Christensen S, Ekelund F, Sorensen SJ, Muller S, Bloem J (2001) An examination of the biodiversity-ecosystem function relationship in arable soil microbial communities. Soil Biol Biochem 33:1713-1722

Guo RY, Chen Q, Li XL (2005) The influence of soil microorganism community on the soil healthy and disease suppressiveness. China Veg 138:78-82

Guo HB, Cui XM, An N, Cai GP (2010) Sanchi ginseng (Panax notoginseng (Burkill) FH Chen) in China: distribution, cultivation and variations. Genet Resour Crop Evol 57(3):453-460

Gyaneshwar P, Kumar GN, Parekh LJ, Poole PS (2002) Role of soil microorganisms in improving $P$ nutrition of plants. Food security in nutrient-stressed environments: exploiting plants' genetic capabilities. Springer, Netherlands, pp 133-143

Hao X, Jiang R, Chen T (2011) Clustering 16S rRNA for OTU prediction: a method of unsupervised Bayesian clustering. Bioinformatics 27:611-618

Hao Z, Fayolle L, van Tuinen D, Chatagnier O, Li X, Gianinazzi S, Gianinazzi-Pearson V (2012) Local and systemic mycorrhiza-induced protection against the ectoparasitic nematode Xiphinema index involves priming of defence gene responses in grapevine. J Exp Bot 63(10):3657-3672

Henrik Nilsson R, Tedersoo L, Lindahl BD, Kjøller R, Carlsen T, Quince C, Abarenkov K, Pennanen T, Stenlid J, Bruns T, Larsson KH, Kõljalg U, Kauserud H (2011) Towards standardization of the description and publication of nextgeneration sequencing datasets of fungal communities. New Phytol 191(2):314-318

Jeffries P, Gianinazzi S, Perotto S, Turnau K, Barea JM (2003) The contribution of arbuscular mycorrhizal fungi in sustainable maintenance of plant health and soil fertility. Biol Fertil Soils 37(1):1-16

Lauber CL, Hamady M, Knight R, Fierer N (2009) Pyrosequencing-based assessment of soil $\mathrm{pH}$ as a predictor of soil bacterial community structure at the continental scale. Appl Environ Microbiol 75(15):5111-5120

Li T, Hu YJ, Hao ZP, Li H, Wang YS, Chen BD (2013) First cloning and characterization of two functional aquaporin genes from an arbuscular mycorrhizal fungus Glomus intraradices. New Phytol 197(2):617-630

Lugtenberg B, Kamilova F (2009) Plant-growth promoting rhizobacteria. Annu Rev Microbiol 63:541-556

Ma L, Cao YH, Cheng MH, Huang Y, Mo MH, Wang Y, Yang JZ, Yang FX (2013) Phylogenetic diversity of bacterial endophytes of Panax notoginseng with antagonistic characteristics towards pathogens of root-rot disease complex. Antonie Van Leeuwenhoek 103(2):299-312

Mao ZS, Long YJ, Zhu YY, Zhu SS, He XH, Chen ZJ (2014) First report of Cylindrocarpon destructans var. destructans causing black root rot of sanqi (Panax notoginseng) in China. Plant Dis 98(1):162

McLean EO, Watson ME (1985) Soil measurements of plantavailable potassium. In: Munson RD (ed) Potassium in agriculture. CSSA SSSA, Madison, pp 277-308
Miao ZQ, Li SD, Liu XZ, Chen YJ, Li YH, Wang Y, Guo RJ, Xia ZY, Zhang KQ (2006) The causal microorganisms of Panax notoginseng root rot disease. Sci Agric Sin 39(7):1371-1378

Nitta T (1991) Diversity of root fungal floras: its implications for soil-borne diseases and crop growth. Jpn Agric Res Q 25(1):6-11

O'Brien HE, Parrent JL, Jackson JA, Moncalvo JM, and Vilgalys R (2005) Fungal community analysis by large-scale sequencing of environmental samples. Appl Environ Microbiol 71(9):5544-5550

Oksanen J (2011) Multivariate analysis of ecological communities in $R$ : vegan tutorial. $R$ package version 1(7)

Olden JD, Poff NL, Douglas MR, Douglas ME, Fausch KD (2004) Ecological and evolutionary consequences of biotic homogenization. Trends Ecol Evol 19(1):18-24

Page AL, Miller RH, Keeney DR (1982) Total carbon, organic carbon and organic matter. In: American Society of Agronomy (ed) Methods of soil analysis. part 2, agronomy. American Society of Agronomy, Madison, pp 539-579

Phillips JM, Hayman DS (1970) Improved procedures for clearing roots and staining parasitic and vesicular-arbuscular mycorrhizal fungi for rapid assessment of infection. Trans Br Mycol Soc 55(1):158

Pruesse E, Quast C, Knittel K, Fuchs BM, Ludwig W, Peplies J, Glöckner FO (2007) SILVA: a comprehensive online resource for quality checked and aligned ribosomal RNA sequence data compatible with ARB. Nucleic Acids Res 35(21):7188-7196

Qiu M, Zhang R, Xue C, Zhang S, Li S, Zhang N, Shen Q (2012) Application of bio-organic fertilizer can control Fusarium wilt of cucumber plants by regulating microbial community of rhizosphere soil. Biol Fertil Soils 48(7):807-816

Rajala T, Peltoniemi M, Pennanen T, Mäkipää R (2012) Fungal community dynamics in relation to substrate quality of decaying Norway spruce (Picea abies [L.] Karst.) logs in boreal forests. FEMS Microbiol Ecol 81(2):494-505

Rescia AJ, Schmitz MF, Martin de Agar P, Pablo CL, Atauri JA, Pineda FD (1994) Influence of landscape complexity and land management on woody plant diversity in northern Spain. J Veg Sci 5(4):505-516

Rodrigues JL, Pellizari VH, Mueller R, Baek K, Jesus EDC, Paula FS, Mirza B, Hamaoli GS, Tsai SM, Feigl B, Tiedje JM, Bohannan BJM, Nüsslein K (2013) Conversion of the Amazon rainforest to agriculture results in biotic homogenization of soil bacterial communities. Proc Natl Acad Sci 110(3):988-993

Roesch LF, Fulthorpe RR, Riva A, Casella G, Hadwin AK, Kent AD, Daroub SH, Camargo FA, Farmerie WG, Triplett EW (2007) Pyrosequencing enumerates and contrasts soil microbial diversity. ISME J 1(4):283-290

Sanguin H, Sarniguet A, Gazengel K, Moënne-Loccoz Y, Grundmann GL (2009) Rhizosphere bacterial communities associated with disease suppressiveness stages of take-all decline in wheat monoculture. New Phytol 184(3):694-707

Schloss PD, Westcott SL, Ryabin T, Hall JR, Hartmann M, Hollister EB, Lesniewski RA, Oakley BB, Parks DH, Robinson CJ, Sahl JW, Stres B, Thallinger GG, Horn DJ, Weber CF (2009) Introducing mothur: open-source, platform-independent, community-supported software for 
describing and comparing microbial communities. Appl Environ Microbiol 75(23):7537-7541

Stewart CN, Via LE (1993) A rapid CTAB DNA isolation technique useful for RAPD fingerprinting and other PCR applications. Biotechniques 14(5):748-750

Sun HX, Qin F, Ye YP (2005) Relationship between haemolytic and adjuvant activity and structure of protopanaxadiol-type saponins from the roots of Panax notoginseng. Vaccine 23(48):5533-5542

Teixeira LC, Peixoto RS, Cury JC, Sul WJ, Pellizari VH, Tiedje J, Rosado AS (2010) Bacterial diversity in rhizosphere soil from Antarctic vascular plants of Admiralty Bay, maritime Antarctica. ISME J 4(8):989-1001

Van Bruggen AHC, Semenov AM (1999) A new approach to the search for indicators of root disease suppression. Australas Plant Pathol 28:4-10

Van Elsas JD, Garbeva P, Salles J (2002) Effects of agronomical measures on the microbial diversity of soils as related to the suppression of soil-borne plant pathogens. Biodegradation 13(1):29-40 van Elsas JD, Jansson JK, Trevors JT (2007) Modern soil microbiology. CRC Press, Boca Raton

Vigo C, Norman JR, Hooker JE (2000) Biocontrol of the pathogen Phytophthora parasitica by arbuscular mycorrhizal fungi is a consequence of effects on infection loci. Plant Pathol 49(4):509-514

Vitale A, Aiello D, Guarnaccia V, Perrone G, Stea G, Polizzi G (2012) First report of root rot caused by Ilyonectria (=Neonectria) macrodidyma on avocado (Persea americana) in Italy. J Phytopathol 160(3):156-159

Woolson RF, Clarke WR (2011) Statistical methods for the analysis of biomedical data. Wiley, New York

Zeller V, Bardgett RD, Tappeiner U (2001) Site and management effects on soil microbial properties of subalpine meadows: a study of land abandonment along a north-south gradient in the European Alps. Soil Biol Biochem 33(4):639-649 